\title{
Non Absorbable Suture Should be Avoided When Operating on the Biliary Tree
}

Kirby G, Macano C, Sitaramachandra Murthy $\mathrm{N}^{*}$ and Perry A

General Surgery, Heart of England NHS Foundation Trust, UK

\section{Image Article}

Non-absorbable and braided sutures should be avoided whilst operating on the bile duct, for example when closing a choledochotomy or ligatisng the cystic duct. Suture material may migrate into the lumen of the duct over time. Foreign objects may act as a nidus for stone formation [1]. This complication is demonstrated by the Figure 1 below: an intra-operative cholangiogram demonstrating choledocholithiasis, and the stone extracted at laparoscopic bile duct exploration measuring $24 \mathrm{~mm}$, which had formed around a braided suture used during open cholecystectomy 37 years previously in Poland.

\section{References}

1. Beardsley C, Lim J, Gananadha S (2012) Nonabsorbable suture material in the biliary tract. J Gastrointest Surg 16: 2182-2183.

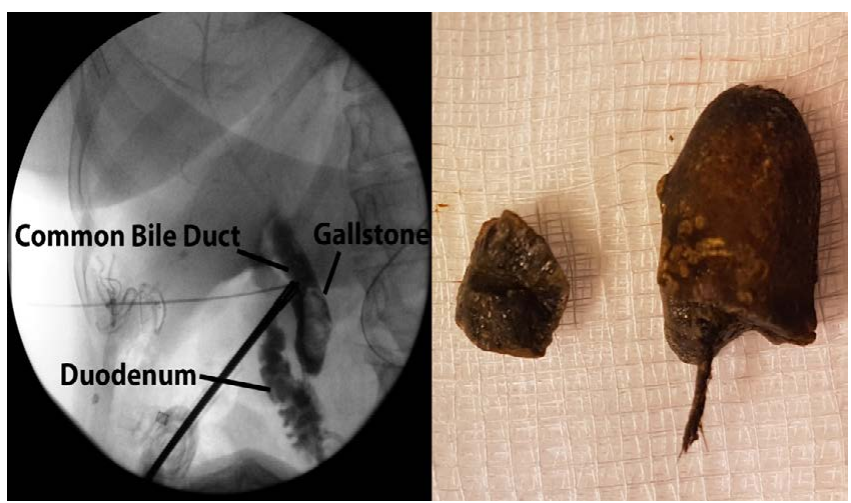

Figure 1: Represents an intra-operative cholangiogram.

${ }^{*}$ Corresponding author: Sitaramachandra Murthy N, Senior Clinical Fellow, General Surgery, Heart of England NHS Foundation Trust, General Surgery, United Kingdom, Tel: 00441162434120; E-mail: murthy.nyasavajjala@nhs.net

Received January 07, 2017; Accepted January 17, 2017; Published January 27 , 2017

Citation: Kirby G, Macano C, Sitaramachandra Murthy N, Perry A (2017) Non Absorbable Suture Should be Avoided When Operating on the Biliary Tree. Med Rep Case Stud 2: i102. doi: 10.4172/2572-5130.1000i102

Copyright: ( 2017 Kirby G, et al. This is an open-access article distributed under the terms of the Creative Commons Attribution License, which permits unrestricted use, distribution, and reproduction in any medium, provided the original author and source are credited. 